\title{
Antibakterijski učinak preparata „Sanosil super25" na višestruko rezistentne bakterije Acinetobacter baumannii i Klebsiella pneumoniae
} \author{
Acinetobacter baumannii and Klebsiella pneumoniae \\ Ana Kovačić ${ }^{1}$ Jasna Hrenović ${ }^{2}$, Ivana Goić-Barišić ${ }^{3}$, Miroslav Barišić \\ ${ }^{1}$ Nastavni zavod za javno zdravstvo Splitsko-dalmatinske županije, Split \\ ${ }^{2}$ Sveučilište u Zagrebu, Prirodoslovno-matematički fakultet, Biološki odsjek, Zagreb \\ ${ }^{3}$ Sveučilište u Splitu, Medicinski fakultet i Klinički bolnički Centar Split, Split \\ ${ }^{4}$ Dom zdravlja Splitsko-dalmatinske županije, Ordinacija dentalne medicine Stari Grad, otok Hvar
}

Antibacterial effect of "Sanosil super25” on multiple resistant bacteria

Ključne riječi:
Acinetobacter baumannii
Klebsiella pneumoniae
dezinfekcija
Sanosil super25
Keywords:
Acinetobacter baumannii
Klebsiella pneumoniae
disinfection
Sanosil super25

Primljeno: 05-05-2020

Received: 05-05-2020

Prihvaćeno: 07-06-2020

Accepted: 07-06-2020

$\triangle$ Dopisni autor:

Doc. dr.sc. Ana Kovačić, dipl.ing.biol.

Nastavni zavod za javno zdravstvo Splitsko-dalmatinske

županije, Vukovarska 46, 21000 Split

E-mail:ana.kovacic@nzjz-split.hr

\begin{abstract}
Sažetak
Višestruko rezistentne bakterije, uzročnici hospitalnih infekcija, kao što su Acinetobacter baumannii i Klebsiella pneumoniae, predstavljaju globalni problem 21. stoljeća. Osobito zabrinjava sve učestalija pojava otpornosti ovih mikroorganizama na komercijalno dostupne dezinficijense. Cilj našeg istraživanja bio je utvrditi učinkovitost dezinfekcije proizvoda "Sanosil super25", u odnosu na vodikov peroksid i to na višestruko rezistentne izolate A. baumannii i K. pneumoniae. Ispitane su vrijednosti MTC (maksimalno tolerirajuća koncentracija); MIC (minimalna inhibirajuća koncentracija) i MBC (minimalna baktericidna koncentracija). MTC Sanosila (<1.25 ppm) bila je dvostruko manja u odnosu na vodikov peroksid. MIC-e Sanosila (1.25 ili <1.25 ppm) su bile 4 puta manje u odnosu na vodikov peroksid. MBC koja rezultira izostankom vijabilnih bakterija za Sanosil je bila $<1.25$ ppm već nakon 5 min kontakta, što je barem 8 puta niža koncentracija u odnosu na vodikov peroksid. Rezultati su pokazali da je Sanosil super25 bio učinkovitiji u sve tri kategorije, u odnosu na vodikov peroksid.
\end{abstract}

\begin{abstract}
Multi-resistant bacteria, the causes of nosocomial infections, such as Acinetobacter baumannii and Klebsiella pneumoniae, represent a global problem of the 21st century. The increasing resistance of these microorganisms to commercially available disinfectants is of a particular concern. The aim of our study was to determine disinfection effectiveness of the product "Sanosil super25", in relation to hydrogen peroxide, to multiple resistant isolates of $A$. baumannii and K. pneumoniae. The tested parameters were: MTC values (maximum tolerated concentration); MIC (minimum inhibitory concentration) and MBC (minimum bactericidal concentration). The MTC of Sanosil ( $<1.25$ ppm) was twice as low as that of hydrogen peroxide. Sanosil MICs (1.25 or $<1.25$ ppm) were 4-fold lower than hydrogen peroxide. The MBC resulting in the absence of viable bacteria for Sanosil was $<1.25 \mathrm{ppm}$ after only 5 minutes of contact, which is at least 8 times lower concentration than hydrogen peroxide. The results showed that Sanosil super 25 was more effective in all three categories, compared to hydrogen peroxide.
\end{abstract}

\section{Uvod}

Pojava višestruko rezistentnih bakterija, kao uzročnika hospitalnih infekcija, postala je globalni svjetski problem 21. stoljeća i znanstvenici ulažu iznimne napore kako bi pronašli učinkoviti način njihovog uklanjanja. Među takvim „ESKAPE” bakterijama, koje su dijelom „izmakle” djelovanju antibiotika, vodeće mjesto zauzimaju Acinetobacter baumannii i Klebsiella pneumoniae $^{[1,2,3]}$. Osobito je značajan razvoj rezistencije ovih bakterija na karbapeneme koji se smatraju zadnjom linijom obrane u liječenju oboljelih ${ }^{[3]}$. Rezistencija na karbapeneme kliničkih izolata $A$. baumannii u Hrvatskoj iznosila je više od 90\% u 2018. godini, a smrtnost od ovog uzročnika u jedinicama intenzivnog liječenja može biti i preko $75 \%{ }^{[2,3]}$. Sojevi bakterija, koji su otporni na djelovanje antibiotika, selektiraju se u bolničkoj sredini i smatra se da su takva mjesta ishodišta epidemija. Međutim, ostaje nejasno postoji li možda stanište takvih mikroorganizama i u okolišu ${ }^{[2]}$. Ovo pitanje postaje sve značajnije zadnjih godina jer su višestruko rezistentni izolati A. baumannii i K. pneumoniae pronađeni u okolišu, gdje mogu preživjeti i kroz nekoliko mjeseci. Sojevi A. baumannii, genetski vrlo srodni kliničkim izolatima, pronađeni su u rijeci 
Savi, otpadnoj vodi Kliničkog bolničkog centra Split, kao i otpadnoj vodi grada Zagreba ${ }^{[3-7]}$. U Hrvatskoj je, u okolišu, nedavno po prvi puta pronađen i soj K. pneumoniae rezistentan na karbapeneme, i to u vodotoku rijeke Krapine. Istraživanje je pokazalo da je ovaj izolat bio sposoban preživjeti 50 dana u autoklaviranoj vodi rijeke $^{[6]}$. Istraživanje, koje su proveli Štimac i sur., ${ }^{[8]}$ koristeći K. pneumoniae Caroli pokazalo je kako ovaj soj u destiliranoj vodi, vodi iz slavine i morskoj vodi, može preživjeti i do 6 mjeseci.

Učinkovita dezinfekcija i uklanjanje mikroorganizama otpornih na antibiotike iz bolničke sredine nužna je kako bi se uspostavio nadzor nad bolničkim infekcijama i spriječilo širenje rezistencije na ostale mikroorganizme. Ono što zabrinjava je sve veća otpornost $A$. baumannii na komercijalno dostupne dezinficijense, kao što su benzalkonijev klorid i klorheksidin, ali i na one koji su na bazi fenola i glukonata, osobito ako se ne koriste $\mathrm{u}$ preporučenoj koncentraciji ${ }^{[2,9]}$. Primjena pare vodikova peroksida, uz ostale mjere kontrole bolničkih infekcija, pokazala je dobre rezultate u suzbijanju epidemije ${ }^{[10]}$. Otpornost na djelovanje dezinficijensa može se dovesti u vezu sa sposobnošću stvaranja biofilma ${ }^{[2,11]}$. Multicentrično istraživanje, provedeno u Hrvatskoj 2015. g., pokazalo je kako je čak 70\% kliničkih izolata A. baumannii imalo sposobnost stvaranja biofilma ${ }^{[12]}$. U istraživanju koje su proveli Ivanković $\mathrm{i}$ dr. ${ }^{[9]}$ dokazano je da su izolati $A$. baumannii, koji su stvorili biofilm na keramičkim pločicama, bili znatno otporniji na dezinficijense od onih koji su stvorili biofilm na staklu. Ovo istraživanje upućuje na to kako su upravo keramičke pločice u zdravstvenim ustanovama moguće stanište višestruko rezistentnih bakterija.

Cilj ovog istraživanja bio je utvrditi učinkovitost primjene komercijalno dostupnog sredstva za dezinfekciju „Sanosil super25” na višestruko rezistentne izolate A. baumannii i K. pneumoniae.

\section{Materijal i metode}

\section{Dezinficijensi}

Za usporedbu antibakterijske aktivnosti Sanosil super25 (Sanosil AG, Švicarska) korišten je 30\%-tni vodikov peroksid $\mathrm{H}_{2} \mathrm{O}_{2}$ (Sigma-Aldrich, Njemačka). Sanosil super25 (u tekstu dalje Sanosil) je višekomponentno sredstvo za dezinfekciju koje sadrži 50\% vodikovog peroksida i $0.05 \%$ srebra (www.sensamed.hr).

\section{Bakterijski izolati}

U pokusima su korišteni okolišni izolati bakterija $A$. baumannii (izolat Sava4) ${ }^{[5]}$ i K. pneumoniae (izolat $9 / 1)^{[6]}$. Izolat $A$. baumannii je pronađen u vodi rijeke Save i otporan je na niz antibiotika, kao što su karba- penemi, fluorokinoloni, aminoglikozidi i penicilini/ inhibitori ß-laktamaze. Metodom MLST (engl. multi-locus sequence typing) otkriven je njegov visok stupanj srodnosti s kliničkim izolatima $A$. baumannii. Izolat $K$. pneumoniae izdvojen je iz vode rijeke Krapine i prvi je KPC (K. pneumoniae carbapenemase) izolat pronađen u okolišu u Hrvatskoj. Otporan je na ampicilin, amoksicilin/klavulansku kiselinu, piperacilin/tazobaktam, sve cefalosporine, sve karbapeneme, trimetoprim-sulfametoksazol, ciprofloksacin, gentamicin i amikacin. I kod ovog je izolata utvrđen visoki stupanj srodnosti s kliničkim izolatima, metodom gel elektroforeze u pulsirajućem električnom polju (engl. pulsed field gel electrophoresis - PFGE).

\section{Postava pokusa}

Izolati A. baumannii i K. pneumoniae umnoženi su odvojeno na neselektivnoj hranjivoj podlozi Nutrient agar (Biolife, Italija) pri $41^{\circ} \mathrm{C}$ tijekom $24 \mathrm{~h}$. Biomasa svake bakterije suspendirana je u $100 \mathrm{~mL}$ autoklavirane komercijalno dostupne prirodne izvorske vode kako bi se dobila početna koncentracija oko $10^{7}$ kolonija (engl. CFU - colony forming units) po jednom $\mathrm{mL}$ otopine. Početna koncentracija bakterija u suspenziji određena je nakon priprave serije decimalnih razrjeđenja uzorka, nasađivanja na hranjivi agar, inkubacije $\left(41^{\circ} \mathrm{C} / 24 \mathrm{~h}\right)$ te prebrojavanja kolonija.

Suspenzija svake bakterije raspoređena je u niz sterilnih epruveta od $10 \mathrm{~mL}$, u kojima je načinjena serija dvostrukih razrjeđenja ispitivanog dezinficijensa (koncentracije od 20 do 1.25 ppm). U epruvetu koja je korištena kao pozitivna kontrola nije dodan dezinficijens. Epruvete su ostavljene na sobnoj temperaturi od $22^{\circ} \mathrm{C}$ tijekom 120 min pokusa. Inkubacija na $22^{\circ} \mathrm{C}$ odabrana je s namjerom da se ispitaju rezultati dezinfekcije vode u realnim uvjetima.

Nakon određenog vremena kontakta, iz svake je epruvete uzeto $10 \mu \mathrm{L}$ uzorka, koji je inokuliran u obliku kapljice na Nutrient agar. Inokulirane su ploče inkubirane na $41^{\circ} \mathrm{C}$ tijekom $24 \mathrm{~h}^{[9]}$, nakon čega je očitana antibakterijska aktivnost dezinficijensa kako slijedi. MTC (engl. maximum tolerable concentration) je najveća koncentracija dezinficijensa koja ne utječe na rast bakterija u odnosu na pozitivnu kontrolu (bakterijska suspenzija bez dodatka dezinficijensa). MIC (engl. minimum inhibitory concentration) je najmanja koncentracija dezinficijensa koja uzrokuje vidljivu inhibiciju bakterijskog rasta u odnosu na pozitivnu kontrolu. MBC (engl. minimum bactericidal concentration) je najmanja koncentracija dezinficijensa koja uzrokuje izostanak bakterijskog rasta. 


\section{Rezultati}

Rezultati istraživanja prikazani su u Tablicama 1 i 2.

Tablica 1. Antibakterijsko djelovanje Sanosil Super25 I vodikovog peroksida na A. BaUmanNiI (izolat Sava4). VRijednosti SU IZRAŽEnE U PPM. KonCENTRACIJA A. BAUMANNII LOGCFU / ML= 7.4 \pm 0.1 .

Table 1. Antibacterial activity of Sanosil super25 And hydrogen peroxide on A. BaumanniI (Sava4 isolate). Values are EXPRESSED IN PPM. CONCENTRATION OF A. BAUMANNII LOGCFU / ML $=7.4 \pm 0.1$.

\begin{tabular}{|c|c|c|c|c|c|c|}
\hline \multirow{2}{*}{$\begin{array}{l}\text { Vrijeme kontakta / } \\
\text { Contact time (min) }\end{array}$} & \multicolumn{3}{|c|}{ Sanosil super 25} & \multicolumn{3}{|c|}{ vodikov peroksid } \\
\hline & MTC & MIC & MBC & MTC & MIC & MBC \\
\hline 1 & $<1.25$ & 1.25 & 2.5 & 2.5 & 5 & 10 \\
\hline 5 & $<1.25$ & $<1.25$ & $<1.25$ & 2.5 & 5 & 10 \\
\hline 15 & $<1.25$ & $<1.25$ & $<1.25$ & 2.5 & 5 & 10 \\
\hline 30 & $<1.25$ & $<1.25$ & $<1.25$ & 2.5 & 5 & 10 \\
\hline 60 & $<1.25$ & $<1.25$ & $<1.25$ & 2.5 & 5 & 10 \\
\hline 120 & $<1.25$ & $<1.25$ & $<1.25$ & 2.5 & 5 & 10 \\
\hline
\end{tabular}

TABlica 2. ANTIBAKTERIJSKo DJElovanje SANOSIL SUPER25 I VODIKOVOG PEROKSIDA NA K. PNEUMONIAE (IZOLAT 9/1). VRIJEDNOSTI SU IZRAŽENE U PPM. KONCENTRACIJA K. PNEUMONIAE LOGCFU / ML = 7.0 \pm 0.1 .

Table 2. Antibacterial activity of Sanosil super25 And Hydrogen peroxide on K. pneumoniae (isolate 9/1). VAlues are EXPRESSED IN PPM. CONCENTRATION OF K. PNEUMONIAE LOGCFU / ML = 7.0 \pm 0.1 .

\begin{tabular}{|c|c|c|c|c|c|c|}
\hline \multirow{2}{*}{$\begin{array}{l}\text { Vrijeme kontakta / } \\
\text { Contact time (min) }\end{array}$} & \multicolumn{3}{|c|}{ Sanosil super 25} & \multicolumn{3}{|c|}{ vodikov peroksid } \\
\hline & MTC & MIC & MBC & MTC & MIC & MBC \\
\hline 1 & $<1.25$ & 1.25 & 5 & 2.5 & 5 & 10 \\
\hline 5 & $<1.25$ & $<1.25$ & $<1.25$ & 2.5 & 5 & 10 \\
\hline 15 & $<1.25$ & $<1.25$ & $<1.25$ & 2.5 & 5 & 10 \\
\hline 30 & $<1.25$ & $<1.25$ & $<1.25$ & 2.5 & 5 & 10 \\
\hline 60 & $<1.25$ & $<1.25$ & $<1.25$ & 2.5 & 5 & 10 \\
\hline 120 & $<1.25$ & $<1.25$ & $<1.25$ & 1.25 & 2 & 5 \\
\hline
\end{tabular}

\section{Rasprava}

U ovom je istraživanju ispitan dezinfekcijski učinak preparata Sanosil na čiste kulture rezistentnih bakterija A. baumannii i K. pneumoniae. Iz dobivenih je rezultata vidljivo da je preparat Sanosil bio učinkovitiji $\mathrm{u}$ inhibiciji rasta ispitivanih mikroorganizama, $\mathrm{u}$ odnosu na sam vodikov peroksid. MTC Sanosila $(<1.25 \mathrm{ppm})$ je bila dvostruko manja u odnosu na vodikov peroksid. MIC-e Sanosila (1.25 ili <1.25 ppm) bile su 4 puta manje u odnosu na vodikov peroksid. MBC koja rezultira izostankom vijabilnih bakterija za Sanosil je bila $<1.25$ ppm već nakon 5 min kontakta (Slika 1. i 2.), što je barem 8 puta niža koncentracija u odnosu na vodikov peroksid. Naime, Sanosil super25 djeluje na principu sinergijskog djelovanja vodikovog peroksida i srebra. Vodikov peroksid djeluje oksidativno na lipide, proteine i DNA te staničnu stijenku mikroorganizama, tako da uzrokuje njihovu denaturaci- ju. Taj je učinak pojačan djelovanjem pozitivnih iona srebra koji tvore veze s negativno nabijenim dijelovima stanične stijenke, pri čemu mijenjaju njenu poroznost. Ioni srebra, također, stvaraju disulfidne mostove $s$ aminokiselinama koje sadrže sumpor, pri čemu dolazi do gubitka aktivnosti enzima ${ }^{[13]}$.

Uobičajeni način dezinfekcije vode za piće kao i vode za kupanje i rekreaciju je pomoću natrijevog hipoklorita. Preparati na bazi klora koji se koriste u dezinfekciji vode mogu djelovati korozivno. Jednako tako, postoji opasnost od stvaranja spojeva štetnih za ljudsko zdravlje, ako je takva voda opterećena organskim tvarima $^{[14]}$. U vodoopskrbnim sustavima, gdje postoji opasnost od legionarske bolesti, uz hiperklorinaciju postupak dezinfekcije podrazumijeva zagrijavanje vode do temperature pasterizacije, ali je on često neučinkovit, upravo zbog stvorenog biofilma ${ }^{[15]}$. Jednako 
Slika 1. OdreĐiVAnje MTC, MIC i MBC ACINETOBACTER BAUMANNII NAKON 5 MIN KONTAKTA SA SANOSIL SUPER25 (GORE) I VODIKOVIM PEROKSIDOM (DOLJE).

Figure 1. Determination of MTC, MiC and MBC of Acine-

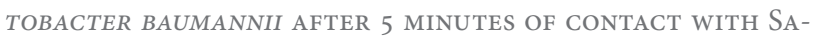
NOSIL SUPER25 (ABOVE) AND HYDROGEN PEROXIDE (BELOW).

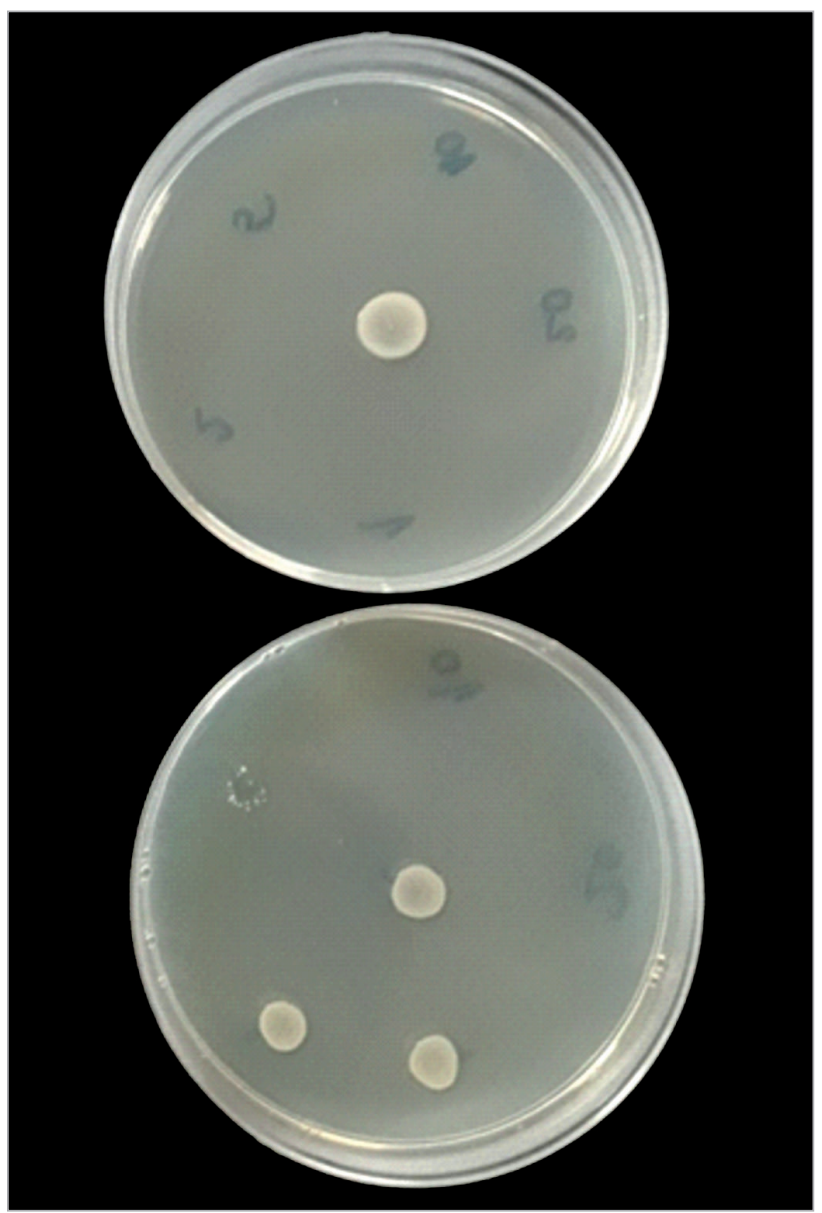

tako, bilježi se sve veći razvoj otpornosti mikroorganizama na uobičajena dezinfekcijska sredstva. Upravo iz ovih razloga, intenzivno se radi na ispitivanju novih preparata koji bi bili učinkoviti u uklanjanju mikroorganizama, a istovremeno neškodljivi za ljude, opremu i okoliš. Jedan od takvih proizvoda je i ovaj na bazi vodikovog peroksida i srebra. Različita su istraživanja pokazala kako upravo ova kombinacija vodikovog peroksida i srebra zadovoljava tražena svojstva - učinkovite dezinfekcije i sigurnosti u medicini i stomatologi$\mathrm{ji}^{[16-19]}$. Problem u svakodnevnoj stomatološkoj praksi predstavlja onečišćenje jedinice zubarskog vodenog sustava. Sanosil super25 je u našem istraživanju pokazao odlične rezultate na rezistentne bakterije $\mathrm{u}$ čistoj kulturi, ali bilo bi vrijedno istražiti učinkovitost ovog preparata na mikroorganizme unutar biofilma, kao i na većem broju klinički značajnih mikroorganizama. Također, osim ovdje ispitane djelotvornosti u prirod-
Slika 2. OdreĐivanje MTC, MIC i MBC Klebsiella pNeuMONIAE NAKON 5 MIN KONTAKTA SA SANOSIL SUPER25 (GORE) I VODIKOVIM PEROKSIDOM (DOLJE).

Figure 2. Determination of MTC, MiC and MBC of KLeBSIELLA PNEUMONIAE AFTER 5 MINUTES OF CONTACT With SANOSIL SUPER25 (ABOVE) AND HYDROGEN PEROXIDE (BELOW).

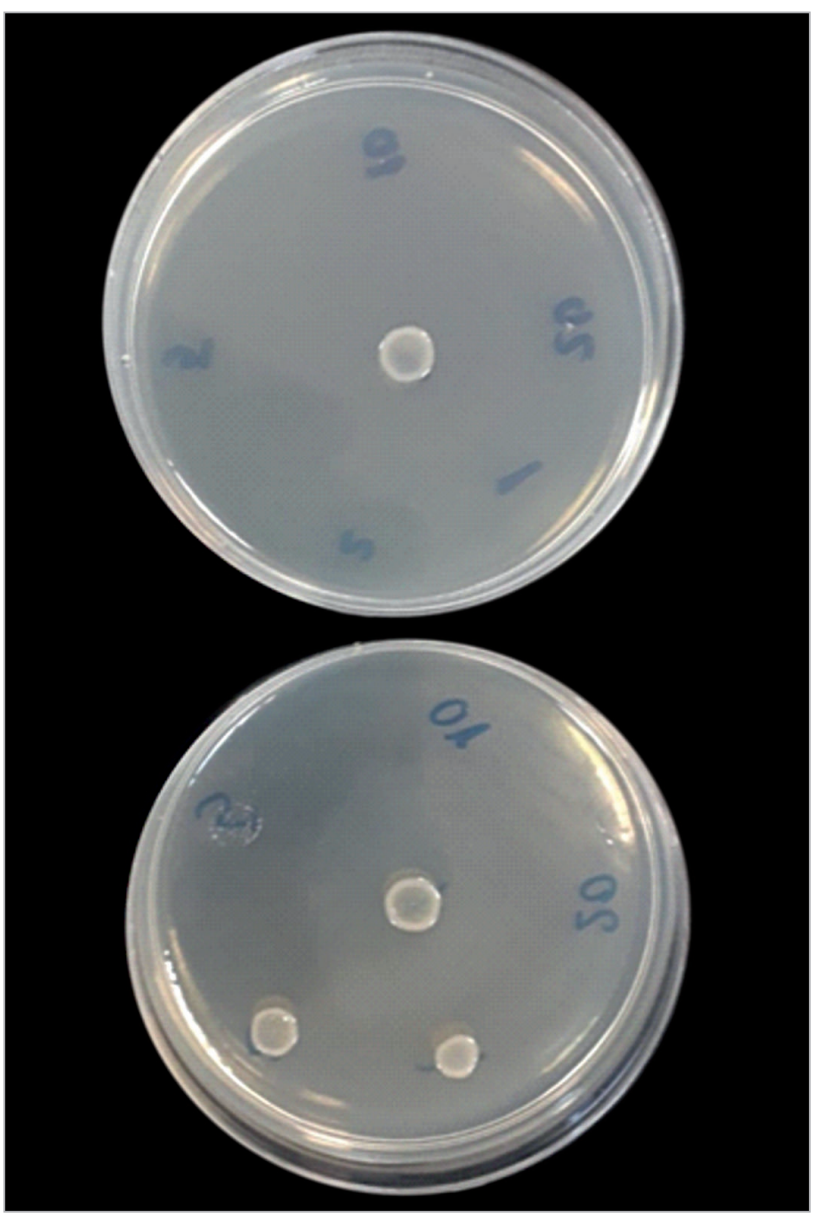

noj izvorskoj vodi, bilo bi korisno ispitati učinkovitost Sanosila i na uzorcima vode s različitom koncentracijom organskog opterećenja koje se može očekivati u bazenskim vodama.

\section{Zahvala}

Ovo je istraživanje provedeno u sklopu projekta Hrvatske zaklade za znanost „Prirodno stanište klinički značajnih Acinetobacter baumannii” (br. IP-2014-09-5656).

\section{LITERATURA}

${ }^{[1]}$ Goić Barišić I, Hrenović J, Kovačić A, Šeruga Musić M. Emergence of oxacillinases in environmental carbapenem-resistant Acinetobacter baumannii associated with clinical isolates. Microb Drug Resist 2016; 22(7): 559-563.

${ }^{[2]}$ Goić Barišić I. Epidemiologija i rezistencija kliničkih izolata A.baumannii u Hrvatskoj tijekom desetogodišnjeg razdoblja što se promijenilo? Medicina fluminensis 2018; 3(54): 268-273. 
${ }^{[3]}$ Dekić S, Hrenović J. Preživljavanje bakterije Acinetobacter baumannii u različitim tipovima vode. Hrvatske vode 2018; 26(103): 35-38.

${ }^{[4]}$ Hrenović J, Durn G, Musić MS, Dekić S, Troskot-Čorbić T, Škorić D. Extensively and multi drug-resistant Acinetobacter baumannii recovered from technosol at a dump site in Croatia. Sci Total Environ 2017; 607-608: 1049-1055.

${ }^{[51]}$ Šeruga Musić M, Hrenović J, Goić-Barišić I, Hunjak B, Škorić $\mathrm{D}$, Ivanković T. Emission of extensively-drug-resistant Acinetobacter baumannii from hospital settings to the natural environment. J Hosp Infect 2017; 96: 323-327.

${ }^{[6]}$ Jelić M, Hrenović J, Dekić S, Goić-Barišić I, Tambić Andrašević A. First evidence of KPC-producing ST258 Klebsiella pneumoniae in river water. J Hosp Infect 2019; 103: 147-150.

${ }^{[7]}$ Kovačić A, Šeruga Musić M, Dekić S, et al. Transmission and survival of carbapenem-resistant Acinetobacter baumannii outside hospital setting. Int J Microbiol 2017; 20: 165-169.

${ }^{[8]}$ Štimac I, Marchesi V, Tomljenović M, Rukavina T. Preživljavanje vrste Klebsiella pneumoniae u različitim uzorcima voda. Hrvatske vode 2009; 71: 13-18.

${ }^{[9]}$ Ivanković T, Goić-Barišić I, Hrenović J. Reduced susceptibility to disinfectants of Acinetobacter baumannii biofilms on glass and ceramic. Arh Hig Rada Toksikol 2017; 68: 99-108.

${ }^{[10]}$ Chmielarczyk A, Higgins PA, Wojkowska-Mach J, et al. Control of an outbreak of Acinetobacter baumannii infections using vaporized hydrogen peroxide. J Hosp Infect 2012; 81: 239-245.

${ }^{[11]}$ Towner KJ. Global epidemiology of Acinetobacter. Clin Microbiol Infect 2007; 13: S47-242.
${ }^{[12]}$ Kaliterna V, Kaliterna M, Hrenović J, Barišić Z, Tonkić M, Goić Barišić I. Acinetobacter baumanii in Southern Croatia: clonal lineages, biofilm formation and resistance patterns. J Infect Dis 2015; 47: 902-907.

${ }^{[13]}$ Tasić S. Efficiency evaluation of the disinfectant based on silver and hydrogen peroxide. J Agric Sci 2009; 54(3): 269-275.

${ }^{[14]}$ Čalić R, Mihovec-Grdić M. Brominated trihalomethanes in drinking water. VI. scientific-professional conference „Water and public water supply", Lovrić, Edo (ed). Mlini, Zagreb: Croatian Institute for Public Health and County Public Institutes, 2002. p. 87-91

${ }^{[15]}$ Farhat M, Moletta-Denat M, Frère J, Onillon S, Trouilhé MC, Robine E. Effects of disinfection on Legionella spp., eukarya, and biofilms in a hot water system. Appl Environ Microbiol 2012; 78: 6850-8.

${ }^{[16]}$ Girolamini L, Dormi A, Pellati T, et al. Advances in Legionella control by a new formulation of hydrogen peroxide and silver salts in a hospital hot water network. Pathogens 2019; 8: 209.

${ }^{[17]}$ Martin NL, Bass P, Liss SN. Antibacterial Properties and Mechanism of Activity of a Novel Silver-Stabilized Hydrogen Peroxide. PLOS ONE 2015; 10(7): e0131345.

${ }^{[18]}$ Pedahzur R, Katzenelson D, Barnea N, et al. The efficacy of long-lasting residual drinking water disinfectants based on hydrogen peroxide and silver. Water Sci Technol 2000; 42(1-2): 293-298.

${ }^{[19]}$ Davoudi M, Ehrampoush MH, Vakili T, Absalan A, Ebrahimi A. Antibacterial effects of hydrogen peroxide and silver composition on selected pathogenic enterobacteriaceae. Int J Env Health Eng 2012;1:23. 